\title{
Regional Connectivity: Opportunities for Bangladesh to be a Transport Hub
}

\author{
Dr. M. Rahmatullah*
}

\begin{abstract}
In a globalized economy, transport cost being a significant determinant of competitiveness, it makes integrated and efficient transport network an essential element of the enabling environment. The integrated transport infrastructure, which South Asia inherited from the British, got fractured initially by the partition of India, and subsequently by its political aftermath and now needs to be rebuilt within the context of greater political harmony in South Asia. Such integration is especially crucial to countries such as Nepal and Bhutan and the regions such as North East India, as this could serve to end their landlocked or semi-isolated status and provide shorter transport and transit access to sea ports. To establish a case for regional transport connectivity in South Asia, an analysis was made of the impact of noncooperation in transport. An assessment was also made of the unique geographical location of Bangladesh having two landlocked countries, such as Nepal and Bhutan and one semilandlocked territory, North East India at the hinterland, and the opportunities this situation provides to Bangladesh. Based on SAARC Regional Multimodal Transport Study (SRMTS) findings, an attempt was made to identify a few strategic routes which could be pursued to provide transport connectivities among the countries of North East Sub-region of South Asia. An indication is made in this paper on the possible benefits that Bangladesh and the other neighboring countries could derive from the regional transport connectivities when established, to show that it would be a win-win situation for all. Finally, the study concludes that the cost of non-cooperation being very high, it would be beneficial for all the concerned countries to go for regional transport connectivity at the earliest. It was, however pointed out that issues related to regional connectivity and transit cannot be resolved in isolation. It needs to be considered together with other unresolved issues, in the areas of water sharing, environment, marine boundary, etc. What is needed for a long lasting solution is the political will and commitment of the leaders of South Asia, who should sit together with an open mind to resolve various issues once for all.
\end{abstract}

\section{Introduction}

The surface transport networks in the North Eastern sub-region of SAARC still continue to remain fragmented due to various historical, political and economic reasons. As a result, the potential of the transport system as the engine of economic growth at the sub-regional level remains largely unrealized. This is happening despite the fact that the basic infrastructure and facilities to establish mutually beneficial intra-regional transport linkages already exist.

Prior to the partition of India in 1947, the trade and commerce of the North-Eastern sub-region with the rest of India and the outside world used to pass through the territories of what is now Bangladesh. Rail and river transit across the erstwhile East Pakistan continued till 1965 when, as a consequence of war between India and Pakistan, all transit traffic were suspended. Although river transit was restored in 1972, no progress has been made on the issue of road and rail transit/transshipment. Bangladesh and its neighboring countries could benefit considerably, if transport connectivity is conceived in the sub-regional context, to link effectively the countries, namely Nepal, Bhutan and North East India (Figure 1). Bangladesh is fortunate to have two sea ports and potential for developing another deep-sea port. But the development of such a deep-sea port can be justified only if there is a sub-regional patronage.

* Former Director, Transport, UN-ESCAP, Bangkok 
Transit or transshipment of cargo across Bangladesh is important to India because it would greatly boost the economy of North East India. In the process, Bangladesh could also greatly benefit from transit fees and transport charges, and in addition may expect huge Indian investment in the transport network development. There are, however, doubts in various quarters in Bangladesh regarding the security implications of such a deal. If such a concern could be addressed, and connectivities could be provided to all the hinterland countries and territories, it could open up for Bangladesh a new source of trading with those countries in transport services.

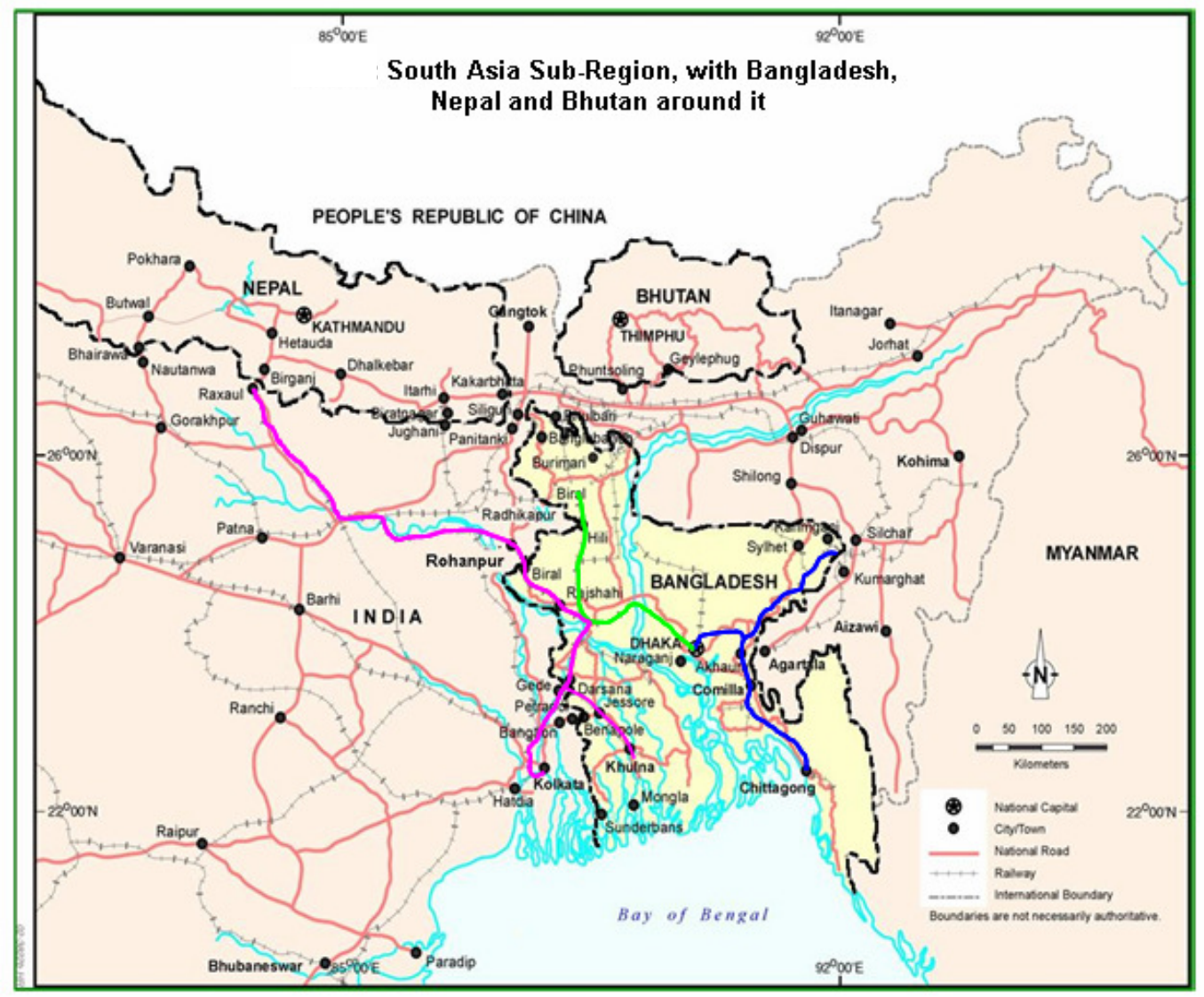

Fig. 1: South Asia Sub-region with Bangladesh, Nepal and Bhutan around it.

Currently, Bangladesh has large trade deficit with India. Trading in transport services with India, for example, could reduce this deficit. In this context, it is crucial to understand clearly that these transport services will have no market elsewhere outside this sub-region. At the same time, it is also important to recognize that these opportunities of trading in transport services may not continue for long. The matter, therefore, deserves urgent attention of the policy makers and the Governments concerned. Under this strategy, Bangladesh could emerge as a "transport hub" of the sub-region comprising Nepal, Bhutan and North East India. The end result could create a win-win situation for all countries involved. With this positive note, this paper has anayzed all possible issues and concerns raised from different sources related to regional connectivity centering Bangladesh and identified several routes that might be considered by the policy makers and concerned professionals. In preparing this paper, the author has consulted many literature, and notable of them are: Dsa (2001), Rahmatullah (2004), RIS (2004), SASEC (2005), Sobhan (2000), Subramanin (2001), UN-ESCAP (2002), Verghese (1998), and Zinn (1999). 


\section{Impacts of Poor Regional Connectivity}

Due to poor regional connectivity between Bangladesh and the neighboring countries of India, Nepal and Bhutan, all the countries and their territories have been losing a great deal in many fronts. For example,

- A container usually takes 20-25 days and occasionally even upto 60 days to move from New Delhi to Dhaka, as the maritime route is via Bombay and Singapore/ Colombo to Chittagong Port and then by rail to Dhaka. But the same container could have been moved to Dhaka within 3-4 days, if direct rail connectivity and operation were there between New Delhi and Dhaka.

- India allowed a transit between Nepal and Bangladesh across the "Chicken neck" and Banglabandh, but for bilateral trade only, and not for the third country trade of Nepal, which now has to pass through already congested Kolkata port. If transport cooperation was there, Nepal could have used Mongla port in Bangladesh, which has spare capacity and conveniently located with a direct broad gauge rail link from Birgunj.

- The shipment of Assam tea to Europe is required to travel $1400 \mathrm{~km}$ to reach Kolkata port through the "Chicken neck", since no agreement exists for India to use the traditional route through Chittagong port which could have been shorter by more than $50 \%$, in terms of distance.

- The Southern border of Tripura State is only $75 \mathrm{~km}$ from Chittagong port, but goods from Agartala are required to travel $1645 \mathrm{~km}$ to reach Kolkata port through the "Chicken neck". If there were transport cooperation between Bangladesh and India, goods would have traveled only around $400 \mathrm{~km}$ across Bangladesh to reach Kolkata, and a much shorter distance to reach Chittagong Port.

- India and Myanmar are jointly implementing "Kaladan project" to link Sittwe port of Myanmar with Mizoram, partly through Kaladan river and partly by road. This would be quite an expensive alternative for India to have access to North East India via Kolkata Port, Sittwe port, Kaladan River and road, as an alternative to the existing route through the chicken neck. If there was transport cooperation with Bangladesh, India could have used a much shorter route across Bangladesh.

Bangladesh and its close door neighbours should try to address these expensive consequences of non-cooperation in transport. The costs of non-cooperation would be high for all the countries in the region. Bangladesh, India, Nepal and Bhutan stand to gain substantially through sub-regional cooperation in transit and transshipment. It would be clearly a win-win situation for all.

Considering India's vital interest in developing the North Eastern sub-region, it should give as many concessions to its neighbours as possible. India should take the lead in settling all existing irritants and disputes. Countries in all parts of the world have disputes with neighbours, but mutually beneficial cooperation is not given up due to this.

\section{Need for Connectivity within a Regional Framework}

In pursuance of the 12th SAARC Summit decision at Islamabad in 2004, to strengthen transport, transit and communication links across the region, the SAARC Regional Multimodal Transport Study (SRMTS) was undertaken by the SAARC Secretariat in 2006. The recommendations of SRMTS were placed before the 14th SAARC Summit in New Delhi, in 2007. The Summit decided that the implementation of these recommendations be pursued by the Transport Ministers of SAARC countries. But the progress so far has not been satisfactory.

Cooperation in transportation cannot be considered in isolation; it has to be considered in the wider context of regional or sub-regional cooperation. This approach has the ramification of wider cooperation, widening the scope of regional interaction and increasing the number of stakeholders. A multi-lateral arrangement inherently contains greater safeguards for smaller and weaker 
countries. SRMTS recommended regional connectivities through all possible modes. Bangladesh being at the centre of the North Eastern sub-region of SAARC, it could consider opening up regional links to other countries in the sub-region through both road and rail, since Inland Water Transport (IWT) routes are already being used to carry both inter-country and transit traffic between India and Bangladesh.

In order to provide the NE-India States, a convenient and shorter access to the sea, India has been asking for their access to Chittagong Port. Similarly, Nepal and Bhutan have also been interested to have access to Mongla Port for their third country trade. Within the spirit of improving SAARC connectivities, Bangladesh should seriously consider providing connectivities to all the three countries and territories simultaneously. While Bangladesh alone can decide about Indian traffic transiting through Bangladesh and about Indian traffic access to Bangladesh Port, the access of Nepal and Bhutan's traffic to Bangladesh Ports will need Indian governments agreement, as these traffic will transit through India.

Although "transit" is a "sensitive term" in Bangladesh, the recent dialogues, seminars and round tables have tried to clarify the position that it is an "economic issue", as such it should not be politicized. Another dimension has emerged through these debates. Transit, now is not considered an "issue" only between Bangladesh and India. Providing transit to both Nepal and Bhutan traffic could bring in added benefit to Bangladesh, and create a win-win situation for all the four countries of North-Eastern sub-region of SAARC.

\section{Transit/Transshipment and Security Issues}

Transit and Transshipment have become sensitive issues in Bangladesh. Some people feel that if transit is given to India, it might create security problem for Bangladesh. Before we proceed further, it is crucial to define these terms such as "transit", "Transshipment" and also the term "corridor" which is frequently used in this connection. "Transit" by definition means "the action of passing through from one place or point to another". In the North-Eastern sub-regional context, "Transit" refers to movement across Bangladesh territory of Indian goods/containers to and from NE-India, using Indian owned transport fleet. On the other hand, "Transshipment" means transfer of cargo/containers from one form of transport to another. In the context of North Eastern Subregion, "Transshipment" means movement of Indian goods/containers across Bangladesh using Bangladesh owned transport fleet.

In the context of regional connectivity, some critics raised the question, whether "Corridor" is being provided to India in the name of "Transit". The term "Corridor" means a strip of territory that runs through that of another state/country and secures access to the sea or to some desired point or place". In view of the various implications of the term "Corridor" including sovereignty, it would not be appropriate for Bangladesh to consider this approach.

An article published in the Daily Star in 1999, made the point that use of Bangladesh territory for the transshipment of Indian goods is "tantamount to granting a corridor to India" (Daily Star, 12 August 1999). According to the writer, "Indian goods will have unhindered passage along a demarcated route, also used by Bangladeshi traffic and that Bangladesh government would have no right to touch or inspect the cargo enroute for illegal, contraband and undesirable goods". Subsequently, the Daily Star published an opinion on the same issue stating that "Transit", "Transshipment" and "Corridor" have the same geopolitical implication in that it "dilutes the geographical barrier for India to its North-East" (Daily Star, 24 August 1999). It also mentioned that the geographical location of the North Eastern Sub-region is the only influence Bangladesh enjoys with India and questioned 'what will happen when we will be bereft of the only leverage in our hand'. However, in the light of the definition of different terms provided in the earlier paragraphs, the views of the above mentioned writers do not seem to be that relevant. In connection with transit and transshipment, certain views have also been expressed. Although these are economic issues, there are security concerns as well, such as increased smuggling of Indian 
goods and increase of Bangladesh's vulnerability to the insurgencies in North Eastern India.

Many of the concerns voiced above can, however, be tackled by properly negotiated agreements for supervision of goods and containers moving across Bangladesh. "Transshipment" based on Railways, IWT and Chittagong port will automatically address many of the concerns voiced above. Modern tools for inspection including scanning can easily ensure that contraband items are not carried as transshipment cargo. Again, if transit and transshipment traffic are carried in containers, it will be possible to significantly reduce the chances of smuggling. Whatever means of transshipment is used, it will be essential to ensure effective independent inspection by different authorities both at entry and exit points to prevent abuse. In case road based transshipment is used, weighbridges have to be installed at all entry and exit points to check overloading, and other elaborate pilferage/leakage prevention mechanisms shall have to be installed.

In the context of "Security" concern linked to "Transit" or "Transshipment, it is important to spell out as to what security issue is being talked about? Did Bangladesh ever face any security problem with the IWT transit given to India? The answer is "no". Similarly, has India ever faced any security problem along the Nepal-Bangladesh transit route? Again, the answer is "no". If one looks at other regional groups, say European Community or to ASEAN sub-region, it is found that traffic is moving over land, across regions/sub-regions without any security problem. Thus, Bangladesh need not be so concerned about "Security" linked with "Transit" or "Transshipment", so long Bangladesh negotiates its agreements with the neighbors with due care and attention.

\section{Appropriate Transport Mode Selection is Critical for Bangladesh}

The issue of transit and/or transshipment needs to be examined against the infrastructure capacity in Bangladesh covering all modes: roads, railways, waterways, and sea and river ports. An examination of transportation infrastructure will focus on available excess capacity and the modes that could be used most beneficially. This will also help to pinpoint specific areas of weaknesses where improvements would be required.

\section{Regional Traffic Should Move Mostly by Railway}

In view of the limitation of road networks in Bangladesh, (see next page), most of the regional traffic/transit traffic movement shall have to be by railway. Bangladesh Railway (BR) has some spare capacity and further capacity can be created with minimal investment. Railway is also environment friendly, safer and cost-effective for long distance movement. Security can also be better ensured in Railway, where goods could be easily moved in containers. There are, however, some gauge differences in railway network of India and Bangladesh, but with modern transshipment facilities, these gauge differences will not pose any problem. There are some constraints in terms of loop length at the Border Stations in Bangladesh which need to be extended.

There are, some lack of compatibility between the rolling stock of Indian and Bangladesh Railways. As such mixing of rolling stock will not be feasible. The entire freight trains shall have to consists of rolling stock of one country, either India or of Bangladesh, to facilitate movement of traffic between origin (near one of the borders) and destination, (near another border). Postshipment inspections instituted in road based transshipment can still be misused for smuggling. But, if transshipment traffic is carried in containers on railways, it will be possible to significantly reduce the chances of smuggling during transshipment. In terms of ease of movement and shifting between different railway gauge systems, containers again provide appreciable advantages.

\section{Road Transport for Movement of High Value and Perishable Goods}

It is highly important to recognize that Bangladesh road network is relatively less developed compared to India. Bangladesh national highways are all 2-lanes only, but extensively used. These 
highways were built based on an axle-load limit of 8.2 tons compared to 10.2 tons axle load limit in India, Nepal and Bhutan. Again most of the trucks used in these countries have 2-axles, and these are highly over-loaded, in most cases. As such it would not be desirable to allow these overloaded vehicles to move along Bangladesh Road network.

To facilitate movement of high value, perishable cargo in small quantities for urgent delivery, container could be used and these could be carried by multi-axle vehicles or truck trailers. For movement of these containers across Bangladesh, the inter-district road transporters from Bangladesh could provide the logistic support and undertake the transshipment of these containers. Goods/containers should, however, be loaded for transshipment only after proper inspection for security, and these need to move under bond and with full insurance coverage.

\section{Movement of Containers by IWT-Cum Road to be Promoted}

In the context of Inland Water Transport (IWT), 2-protocol routes are already in use. But these routes are facing a number of problems which need to be addressed soon, to make IWT more efficient and suitable to carry containers between India and Bangladesh. In addition, Bangladesh could also consider for designating Ashuganj as a new port of transshipment and establish facilities there to transfer containers and goods from IWT to road transport and vice-versa. These containers and goods after proper inspection for security at the transshipment yard, could be carried by truck trailers/multi-axle vehicles, operated by Bangladesh inter-district road transporters, for onwards movement to Indian border at Akhaura, which is only $38 \mathrm{~km}$ away.

\section{Need to Focus on a Few Strategic Routes}

SRMTS has recommended a number of routes to strengthen connectivities among the countries and territories of North-Eastern sub-region of SAARC. However, keeping in mind the resource constraints, it would be advisable to focus attention, in the first phase, on a few routes and land ports. Presented below are 3-most important rail routes, 3-important road routes, and 3-major rail heads, besides 10 land ports which could be opened immediately to facilitate movement of goods and passengers between the countries of the North Eastern sub-region.

\section{Routes for Both Bilateral and Transit Traffic}

Rail Route-1: Mahisasan/Shahbazpur-Kulaura-Akhaura-Chittagong (with a rail link from Akhaura to Agartala)

This rail route (Figure 2) would provide the NE Indian states, a direct access to Bangladesh port of Chittagong. This route would be around $600-700 \mathrm{~km}$ long and would provide more than $50 \%$ savings in travel distance compared to the route to Kolkata through the "Chicken neck". The Kulaura-Mahisasan rail link needs to be re-commissioned before train operation could start. Until such time that Indian Railway Section upto Mahisasan is converted to Broad Gauge (BG) and Shahbazpur-Kulaura-Akhaura-Chittagong section is converted from MG to Dual gauge (DG), transshipment facilities shall have to be installed in India near the border to transfer containers/freights between BG and MG. To facilitate smooth train operation along the route, bilateral/multilateral rail transport agreement shall have to be developed and adopted, besides introduction of simplified customs procedures and IT data transfer facilities at the border.

This regional rail connectivity would benefit both India and Bangladesh considerably. While North East India States will gain access to a conveniently located sea port and each ton of cargo will save more than $50 \%$ of the transport cost and travel time, Bangladesh will benefit from earnings of foreign exchange in terms of rail charges, port charges and transit fee for each container or each ton of cargo. Thus, it would be a win-win situation for both India and Bangladesh. 


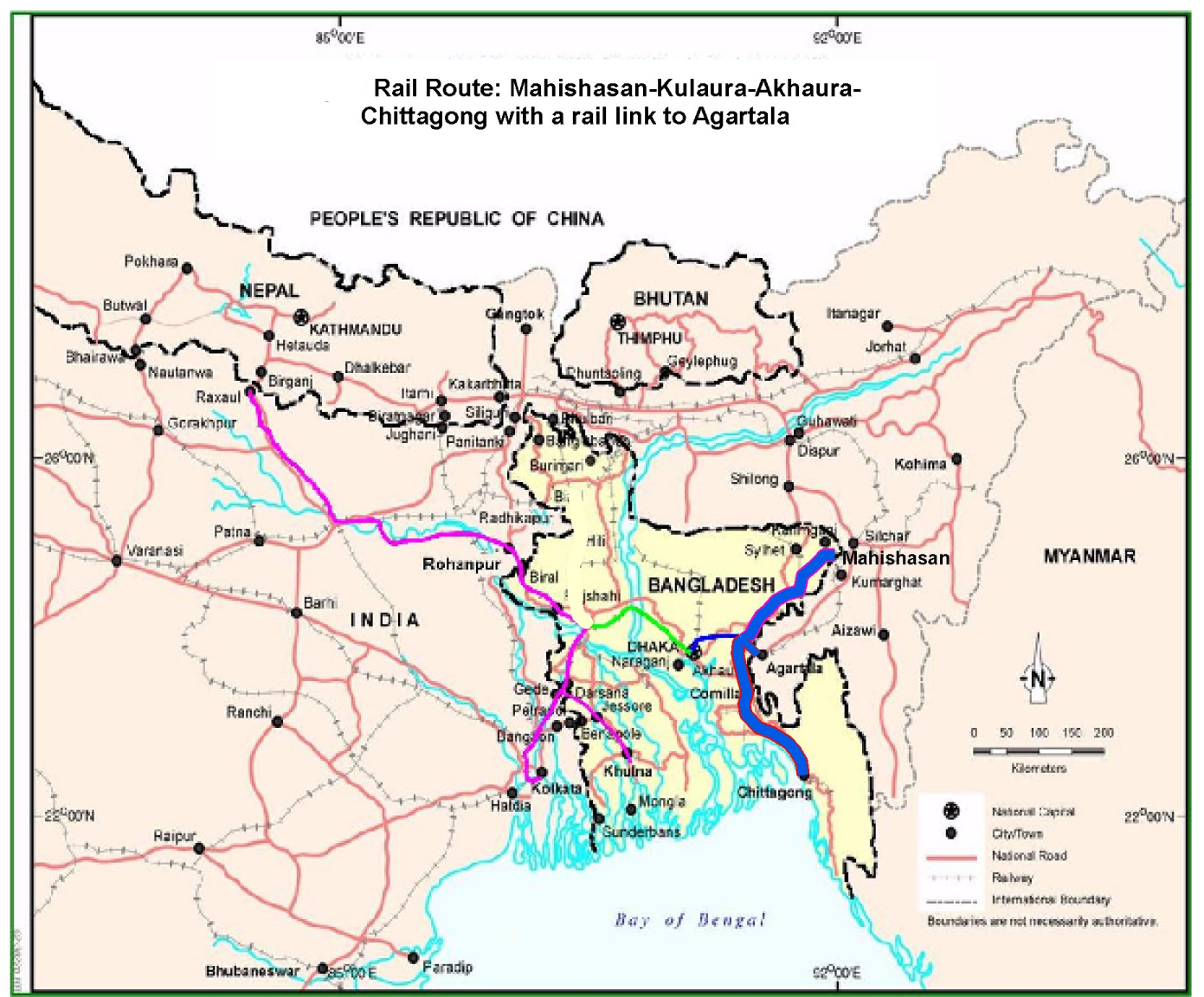

Fig. 2: Kaıl Koute: Mahıshasan-Kulaura-Akhaura-Cittagong with a rail link to Agartala

\section{Rail Route-2: Gede/Darsana-Jamuna Bridge - Tongi - Akhaura - Kulaura -Shahbazpur/ Mahisasan (with a rail link to Agartala)}

This route would provide direct connectivity between Kolkata and North East Indian States, currently, Indian freight trains travel only up to the border stations inside Bangladesh and BR Locomotives pull them inside to certain destinations. BR wagons also do not cross the Indian border, as the rolling stock is incompatible with the air-braked stock of Indian Railways. Present load restriction over Jamuna Bridge in Bangladesh prohibits the movement of fully loaded broad gauge wagons, but allows fully loaded ISO containers to move across Jamuna Bridge, without any load restrictions.

While BG container trains can now move up to Dhaka ICD for transshipment, in the long run, facilities shall have to be established at the proposed Dhirasram ICD (near Tongi), to transfer containers to MG flat wagons for movement upto Shahabazpur/Mahisasan and beyond, until such time that the section between Tongi and Shahbazpur is converted to Dual gauge (DG). As an alternative, possibilities could also be kept open for limited number of containers to move by multi-axle vehicles/truck-trailers from Dhaka ICD onwards to Indian border near Mahisasan. This logistic service could be provided easily by Bangladesh road transporters. For smooth movement of trains across the border, bilateral/multilateral rail transport agreement shall have to be developed and adopted besides introduction of simplified customs procedures and IT data transfer facilities at the border. Figure 3 shows the alignment of this route. 
This rail connectivity will benefit both India and Bangladesh to a large extent. This direct connectivity between Kolkata and NE India will be almost half of the present distance through the chicken neck. As a result, India will gain a lot from the savings in transport cost and travel time. On the other hand, Bangladesh will also have a new source of earning foreign exchange, in terms of rail charges, and transit fee for each container and for each ton of cargo. Since Bangladesh has some spare capacity along the corridor in question, only marginal investment would be needed to carry this transit traffic. Thus, it would be a win-win situation for both Bangladesh and India.

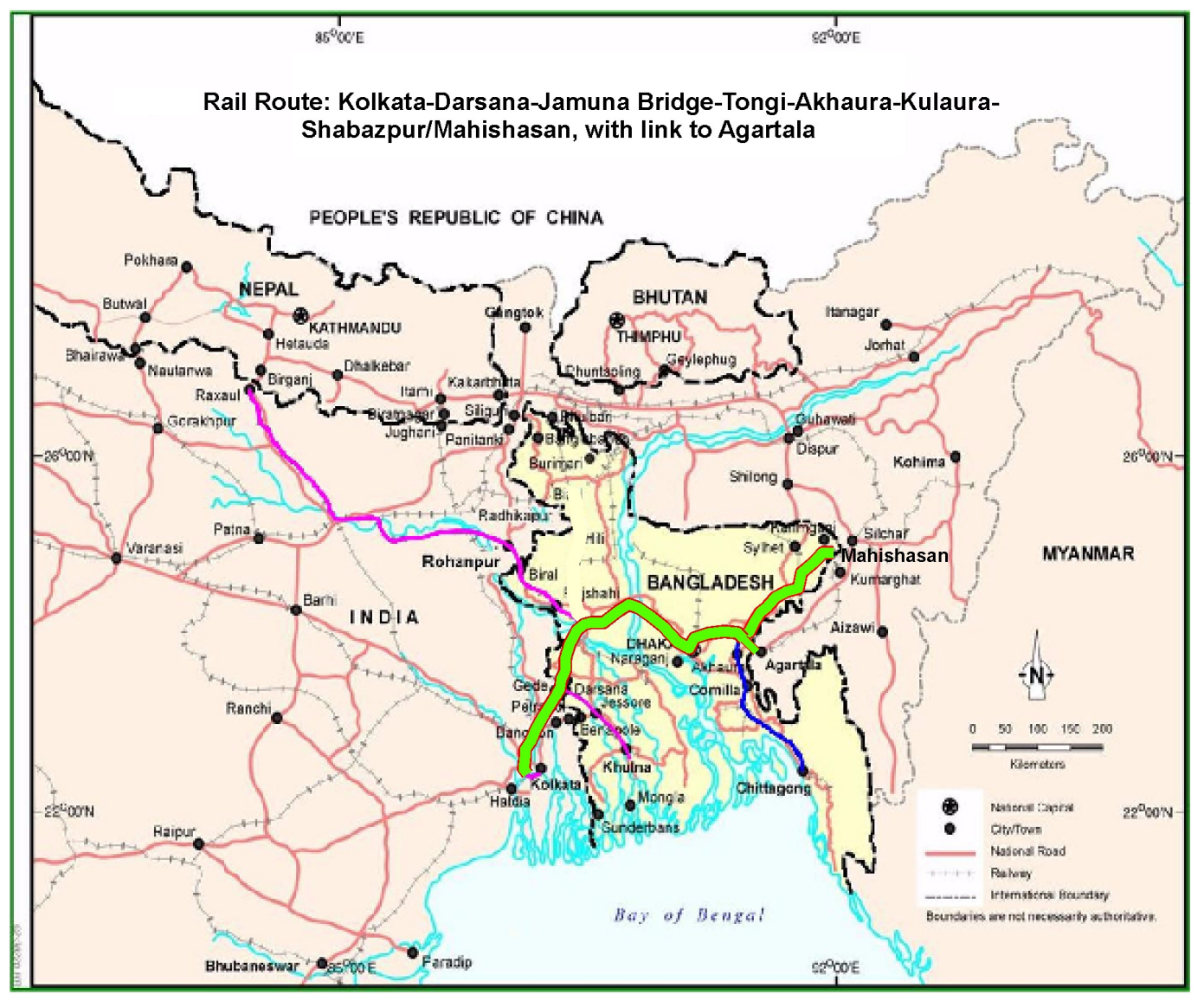

Fig. 3: Rail Route: Kolkata-Darsana-Jamuna Bridge-Tongi-Akhaura-Kulaura-Shabazpur/Mahishasan, with link to Agartala

\section{Road Route-1: Petrapole/Benapole - Jessore-Dhaka (via Road ferry) - Brahmanbaria - Sylhet- Tamabil (with a link to Akhaura/Agartala)}

This route (Figure 4) could in the long run, provide direct road connectivity between Kolkata and North East Indian States. Road transporters could use this route for high value and perishable commodities, as well for small quantities of goods, which are required to reach the destination quickly. Since Bangladesh roads are not yet fully geared to carry heavy axle loads, multi-axle vehicles/truck-trailers shall have to be introduced to avoid damage to road infrastructure. These goods should preferably move in containers and carried by inter-district road transporters of Bangladesh. All containers/goods will be carried only after proper inspection for security, and these will move under bond and with full insurance coverage. Modern facilities with multiple transfer points shall be established at the border for transfer of containers/goods. 
This road route through Bangladesh could bring considerable benefit to the North East Indian States. Savings in travel distance would be around $60 \%$, since the average travel distance between NE-India and Kolkata is around $1400 \mathrm{~km}$ via chicken neck, while the travel distance through Bangladesh would be around 600 to $700 \mathrm{~km}$. Bangladesh would have a new source of earning foreign exchange in terms of road transport charges and transit fee. Thus, it would be a win-win situation for both Bangladesh and India.

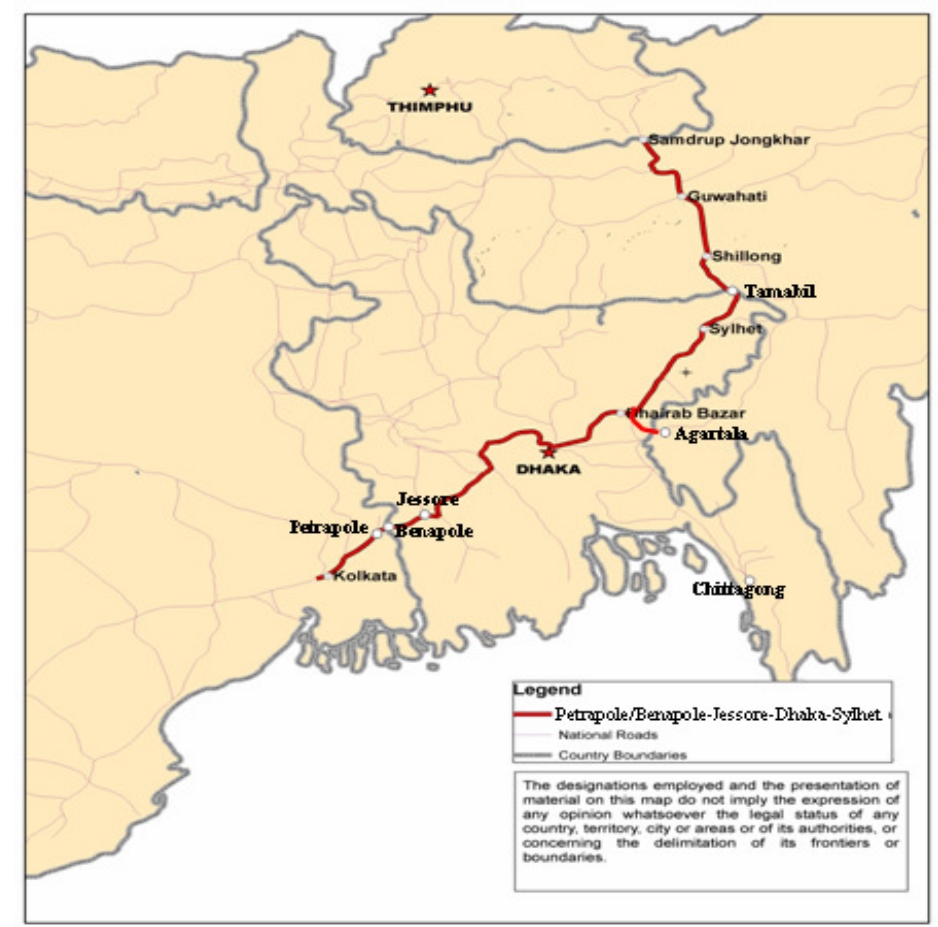

Fig. 4: Road Route: Petrapole-Benapole-Jessore-Dhaka (via Road Ferry)-Bhairab Bazar-Sylhet-Tamabil (with a link to Agartala)

\section{IWT Routes (a): Kolkata-Raimongal-Mongla-Narayanganj-Aricha-Pandu, and}

\section{(b): Kolkata-Raimongal-Mongla-Narayanganj-Bhairab Bazar- Sherpur-Karimganj}

Indian transit traffic across Bangladesh and Indo-Bangladesh bilateral traffic regularly move along the above two designated Inland Water Transport (IWT) Protocol routes provided since 1972, as part of a Trade Agreement signed between India and Bangladesh (Figure 5). Currently, these routes are highly underutilized, partly due to lack of adequate drafts, navigational aids, and partly due to limited number of ports of call and non-renewal of the Protocol for longer periods, a problem which has now been resolved.

Recognizing that the IWT has high potential for carrying both transit and inter-country traffic, it is necessary to assess as to how the above two routes could be made more efficient and competitive with other modes. Both Bangladesh and India should jointly look into the problems of IWT routes and come up with suitable solutions. To make IWT more competitive, one of the immediate actions which could be taken by Bangladesh is to designate "Ashuganj" as a new transshipment port with facilities developed for transferring containers/goods to inter-district multi-axle vehicles/truck-trailers of Bangladesh road transporters, for onward movement to the border at Akhaura. These containers would be loaded to multi-axle trucks only after proper inspection for security and move under bond, with full insurance cover. 
This IWT-cum-Road link could be quite competitive to road transport for certain commodities, and provide a new opportunity to IWT operators and road transporters in Bangladesh to earn additional foreign exchange. On the other hand, India will gain tremendously, through saving in transport cost and travel time. For cargo originating in Tripura State, the travel distance savings would be to the tune of $70 \%$, as the distance through the chicken neck is around $1645 \mathrm{~km}$, while the distance through Bangladesh would be around $500 \mathrm{~km}$. Thus it would be a win-win situation for both Bangladesh and India.

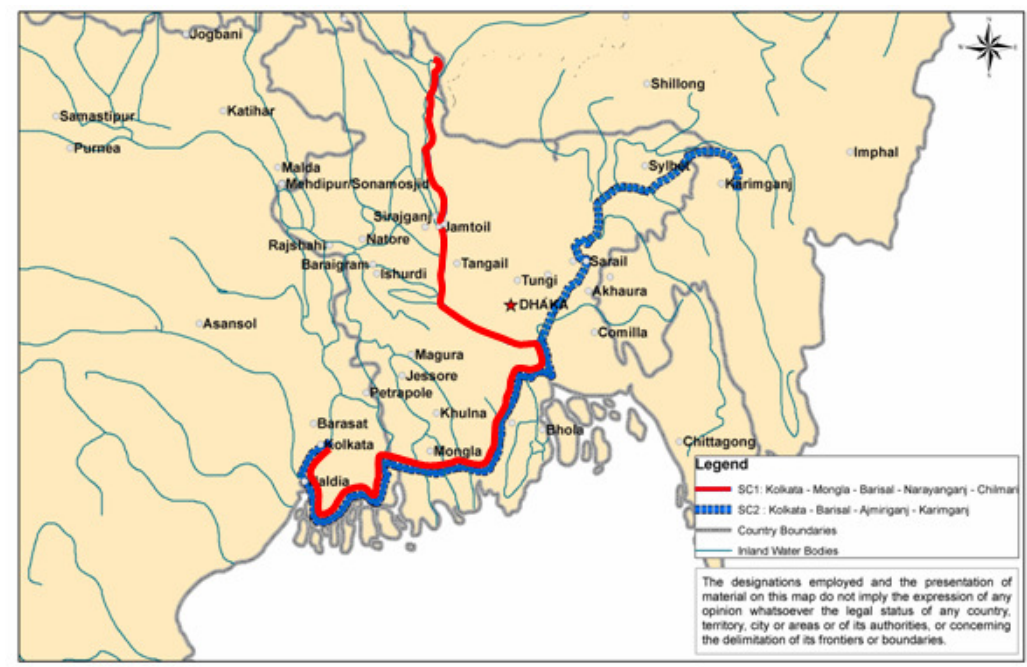

Fig. 5: IWT Routes: Kolkata-Raimongal-Mongla-Narayanganj-(a) ArichaPandu, and (b) Bhairab Bazar-Karimganj

\section{Rail Route-3: Birgunj - Rauxal - Katihar - Singhabad/Rohanpur - Ishwardi - Khulna, with a road link of $38 \mathrm{~km}$ to Mongla Port (Appox. $980 \mathrm{~km}$ )}

This rail route (Figure 6) would provide Nepal traffic a direct BG access to Bangladesh port of Mongla. Compared to road link through Banglabandha which is $1314 \mathrm{~km}$ to Mongla, this rail route will be less than $1000 \mathrm{~km}$, and could provide a cost-effective service, viz-a-viz trucking. A "Multilateral rail transport agreement" would, however, be needed, besides addressing the problems of incompatibility of railway standards to facilitate smooth movement across the border. The containers/goods could be transferred to multi-axle vehicles/truck-trailers at Khulna Junction station for onward movement to Mongla Port. A small scale transfer facilities and storage shall have to be established at Khulna Junction station for smooth handling of containers/goods.

Provision of such a direct rail route for Nepal's third country trade movement through Bangladesh Port of Mongla would, however, bring a win-win situation for all the three countries, Bangladesh, India and Nepal. While India will earn rail charges for each container or each ton of cargo carried by railway between Birgunj (Nepal) and Singhabad (India/Bangladesh border), it can also charge transit fees for the same cargo. In addition, this diversion of third country cargo from Kolkata port to Mongla Port would relieve congestion at Kolkata port, although there would be some loss of earning for the port.

The benefit for Nepal would be the "quick service" that its export/import cargo would get at Mongla port and the reasonable port charges it would be required to pay compared to Kolkata Port. In addition, there would be no waiting required for Nepal's traffic, as Mongla port has some spare capacity. The benefit for Bangladesh would be the port charges, the rail charges and the transit fees that it would charge for each container or for each ton of cargo handled. These would 
be new sources of earning for Bangladesh, because at this point Nepal traffic does not move through Mongla Port. Thus opening up this rail route would create a win-win situation for all the 3-countries involved.

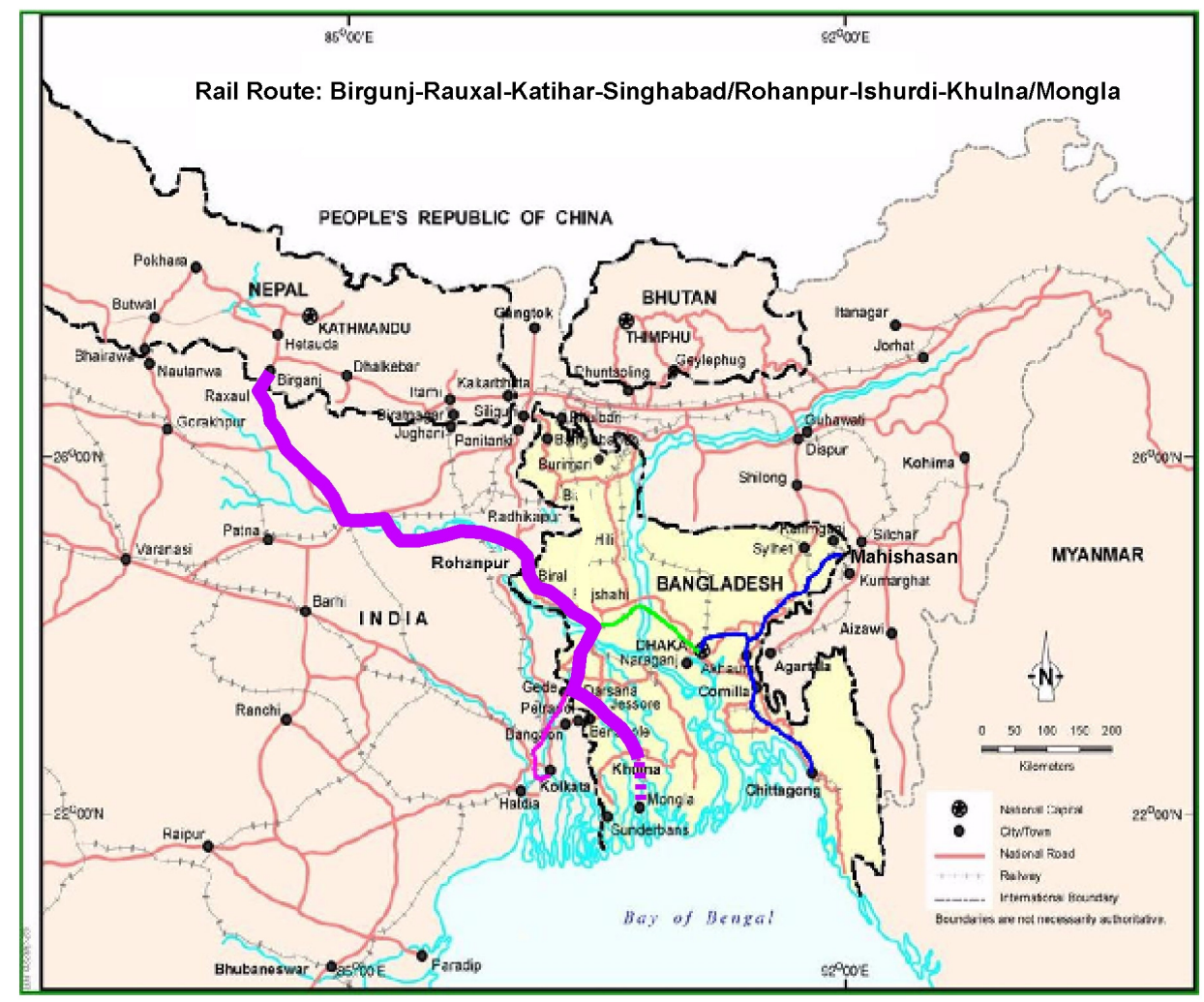

Fig. 6: Rail Route-3: Birgunj-Rauxal-Katihar-Singhabad/Rohanpur-Ishwardi-Khulna, (with a road link to Mongla Port)

\section{Road Route-2:Kakarvita (Nepal) - Phulbari (India) - Banglabandha (Bangladesh) - Bogra - Jessore - Khulna - Mongla Port}

This route (Figure 7) is already being used for bilateral traffic, although very little traffic actually moves. But the third country traffic of Nepal is not allowed to use this route which could have provided Nepal a direct access to Mongla port. It is now proposed to open this route for movement of third country trade of Nepal. Currently Nepal's third country traffic moves entirely through Kolkata port, where it faces congestion.

Since Bangladesh roads are not geared to carry heavy axle load, goods/containers need to be transferred at Banglabandha, and carried in multi-axle vehicles of Bangladesh inter-district road transporters. To make road transport more efficient, modern facilities shall have to be established at Banglabandha, for quick transfer of goods/containers at several points at a time. Loading of goods/containers would be undertaken only after proper inspection for security and these would move under bond with full insurance cover. To facilitate faster clearance of goods/containers, on line customs IT connectivity shall have to be established at Banglabandha, besides efficient warehousing facilities. The main benefit of India will be the availability of Kolkata Port entirely for its won use. India would, however, be able to charge transit fee for $22 \mathrm{~km}$ of route across the chicken neck. Bangladesh will gain in several ways. Besides earning road transport charges, it will also earn port charges, and "Transit fees. 


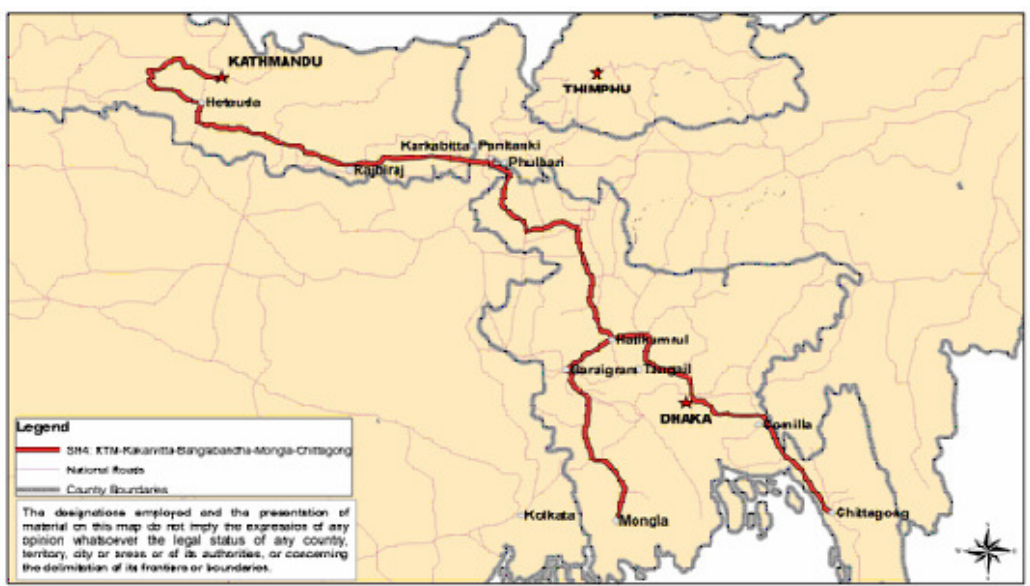

Fig. 7: Road Route-2: Kakarvita (Nepal)-Phulbari (India)-Banglabandha (Bangladesh)Bogra-Jessore-Khulna-Mongla Port

\section{Road Route 3: Thimphu - Phuentsholing - Jaigon - Chengrabandha - Burimari - Rangpur - Bogra - Jessc e - Mongla Port (880 km)}

Since Bhutan does not have any rail system, it is entirely dependent on road transport for its regional connectivity. The above road route (Figure 8) would provide Bhutanese traffic an alternative and shorter access to Mongla port in Bangladesh. To avoid damage to Bangladesh Road network, multi-axle vehicles and/or truck-trailers shall have to be introduced to carry goods and containers. Bangladesh inter-district road transporters could provide this logistic support to carry these goods/containers between Burimari and Mongla Port. These goods/containers would be transferred only after proper inspection for security, and these would move under bond, with full insurance cover. To make road transport more efficient, modern facilities shall have to be established at the land port for quick transfer of goods/containers at several points at a time. To facilitate faster clearance of goods and containers, on-line customs IT connectivity shall have to be established at the land port in Burimari, besides efficient warehousing facilities.

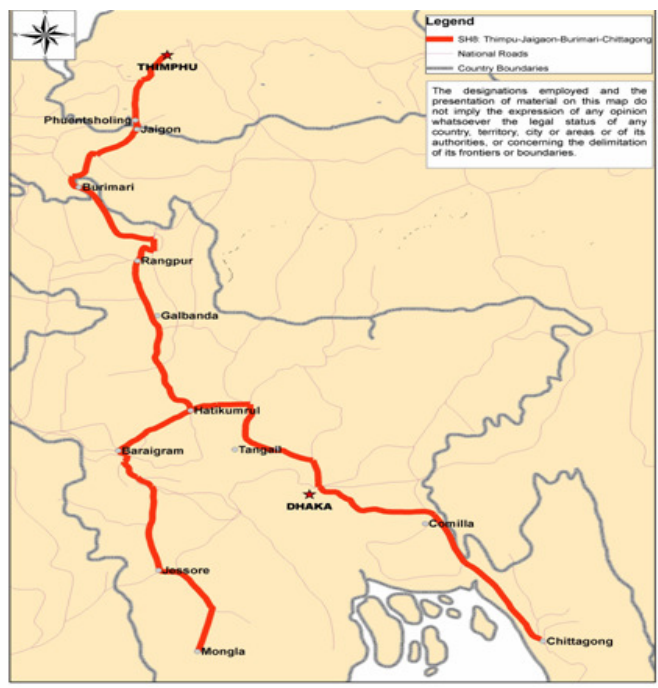

Fig. 8: Road Route 3: Thimphu-Phuentsholing-JaigonChengrabandha-Burimari-Rangpur-Bogra-Jessore-

Mongla Port. 


\section{Routes for bilateral traffic only \\ Rail routes between Bangladesh and India}

In addition to two rail links, namely Gede/Darsana and Mahishasan/Shahbazpur which are already being proposed for both bilateral and transit traffic movement between Bangladesh and India, the following three rail links which are already being used for bilateral trade, could be opened for through movement up to certain destinations within Bangladesh and India (Figure 9).

(1) Petrapole/Benapole BG Rail link

(2) Singhabad/Rohanpur BG Rail link

(3) Radhikapur/Birol BG/MG Rail link

All the major rail-heads, namely Darsana, Benapole, and Rohanpur are having physical barriers, in terms of inadequate loop lengths and yard holding lines. In addition there is restriction on movement of oil tankers and containers across the border by rail. For efficient utilization of rolling stock and to facilitate wider use of railway, consideration should be given to review these restrictions, to promote further regional cooperation in transport. With regard to rail link-3 at Biral, at present it is not possible to use this link effectively until the section Parbatipur-Biral is converted to dual gauge (DG). Bangladesh Railway Master Plan under finalization has already included this conversion as a project to be undertaken urgently.

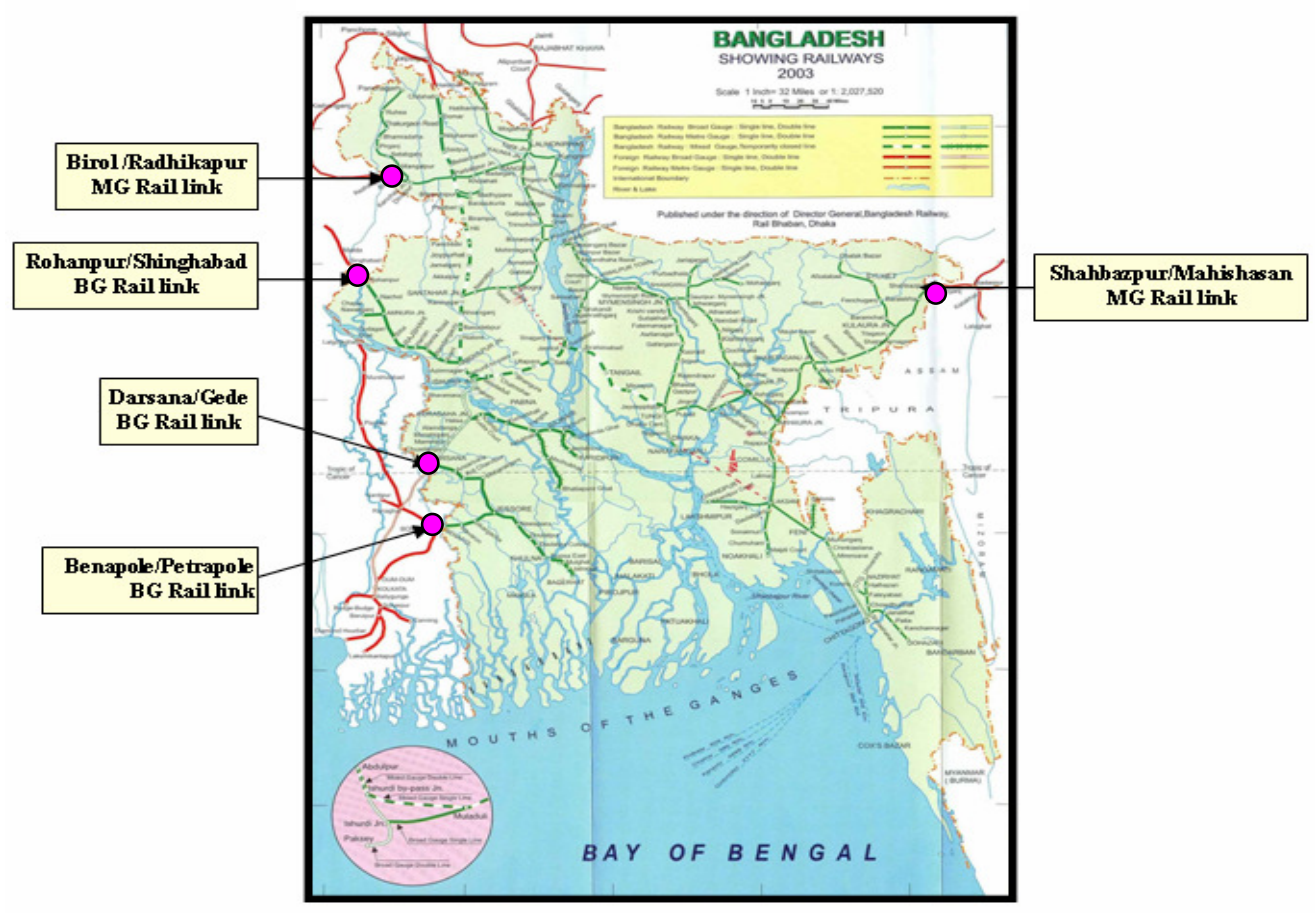

Fig. 9: Rail links for bilateral trade with India

\section{Road based land ports between Bangladesh and India}

The road based land ports, which are already being used for bilateral trade, lack in modern facilities that are necessary for efficient transfer of containers and goods (Figure10). These land ports are: Bhomra, Benapole, Sonamasjid, Hili, Banglabandha, Bhurimari, Haluaghat, Tamabil, Akhaura and Bibir Bazar. 


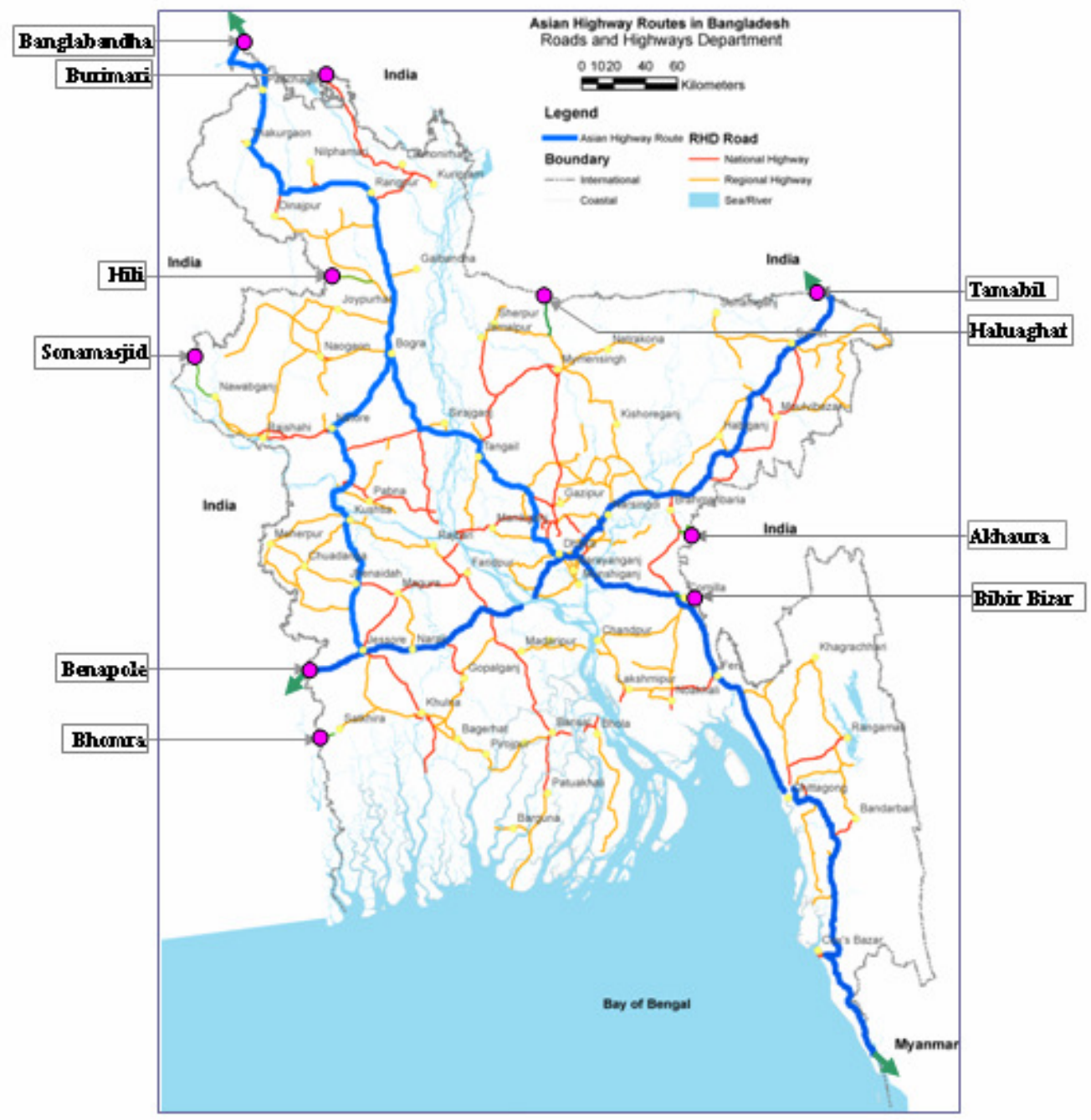

Fig. 10: Road based land ports between Bangladesh and India

Most of these land ports, lack in physical facilities in terms of good quality approach road, parking space for vehicle, adequate immigration facilities, cargo handling equipments, sufficient warehousing facilities post office and telephone facilities, etc., which adversely impact clearance of goods at the land ports. Many of the land ports are linked by LGED roads which have only 12' pavement. The recently completed Road Master Plan for RHD Roads, has, however, recommended that all land ports should have access roads of national highway standard. A number of other facilitation measures such as, simplification and harmonization of customs procedure, adoption of similar documentation at all border points, installation of on-line customs IT connectivity for faster clearance of goods/containers, controlling of overloading of vehicles, etc. are also required to be introduced and enforced.

\section{How to Make Further Progress?}

In order to establish effective regional transport connectivity among the countries of North Eastern sub-region of SAARC, the following initiatives could be pursued to make a headway. 


\section{Mobilization of Political Support}

To establish effective regional transport connectivity, political support is a must. In order to mobilize such a support, it is essential to ascertain the real dimensions of the political constraints and types of reservations. To this end, dialogues could be organized in each of the North Eastern sub-regional countries of South Asia, involving the entire civil society including the Chambers of Commerce and Industries to find the real scope and depth of the political reservations, so that some solutions acceptable to the politicians could be found. Representatives of the Government Intelligence Agencies need to be involved in the dialogues to ascertain if there is any security issue that needs to be addressed. Civil Society Institutions in each of the countries involved, need to take initiative to set the ball rolling.

\section{Various Issues Need to be Addressed Together}

Earlier consultations with some of the SAARC member countries revealed that problems related to regional transport connectivity cannot be resolved in isolation. This needs to be looked into together with other outstanding problems in trade, environment, water sharing, border disputes, international maritime boundary settlements, etc. Strong political commitments of the countries concerned are needed to address these diversified problems together, to find a long lasting solution. This issue may also be discussed at the dialogues referred to above.

\section{Need to Improve Facilitation Measures at the Land Ports/Rail Heads at the Border}

Considerable difficulties exist at the land border crossings. Besides, the physical constraints indicated earlier as part of different routes, other constraints include inefficient customs operations, lack of bilateral/multilateral transport agreements, lack of transparency in inspection procedures, informal payments and inadequate preparation of customs documentation by shippers, etc. None of the borders yet have on-line customs IT connectivity to facilitate faster clearances.

Banking, medical, communication, warehousing, security and fire fighting facilities are deficient and wayside amenities are absent in many of the land ports. Due to lack of adequate parking areas for trucks, vehicles are parked on the road creating acute congestion. At most of the border points, there is only one exit route for both passengers and goods. All these problems need to be addressed properly to facilitate smooth movement across the border.

\section{Awareness Creation Needed About the Cost of Non-Cooperation}

A process of awareness creation through dialogues, about the mutual benefit of regional transport connectivity, or cost of non-cooperation, based on a study could go a long way in persuading the political leadership and the people at large, about the importance of transport connectivity. This study could focus on a number of selected corridors/routes. Estimate of benefit should not be based on diverted traffic only, but also on potential traffic/trade that could be generated once the selected routes are available to regional traffic.

\section{Transport Integration Would Need Nominal Resources Only}

The neighboring countries around Bangladesh, given their physical and cultural proximity and shared history and heritage, form a natural area for transport integration. Most of these countries once formed part of an integrated economy, and their transport system was fully integrated, but they probably constitute one of the less "internally connected" sub-regions in the world today. The integration of transport networks would, therefore, largely involve a reintegration of existing infrastructures, requiring minimum commitment of additional economic resources.

\section{Need To Involve People At Large}

In order to achieve a long lasting solution, it is essential that concerted efforts be made together by all stakeholders: the governments, the private sector and the civil society at large to bring about a change in the political mind set of the leaders, so that a long lasting solution can emerge. The Civil Society Institutions including the Chambers of Commerce and Industries in the member countries 
could be urged to take the initiative to bring the above players together. Unless this challenge of integration is addressed soon with seriousness by all stakeholders, the countries/territories of the North Eastern subregion of SAARC in general, and the land-locked countries/regions in particular, stand the risk of foregoing many of the economic opportunities that the process of globalization could have provided.

\section{Recommendations}

In order to make further progress in the area of regional cooperation in transport, governments both individually and jointly should consider the following issues and take immediate actions on these:

i. Bangladesh may agree to provide transit/transshipment facilities to India by rail and road, similar to IWT (which was provided since 1972).

ii. Bangladesh should agree to provide transit/transshipment facilities to Nepal and Bhutan to have access to its sea port of Mongla, for their third country trade. (Bangladesh needs to seek India's support and agreement to the movement of third country trade of NepalBhutan through Bangladesh port of Mongla).

iii. Bangladesh, India and Nepal should agree to adopt bilateral/multilateral rail transport agreements for through movement of containers/goods across Bangladesh.

iv. To make railway operational as soon as possible, following actions need to be taken on a priority basis: (a) recommissioning of railway link between Mahisasan/Shahabazpur Kulaura, (b) establishment of transshipment facilities, in the long run, at Dhirasram (near Tongi) for transferring containers from BG to MG and vice versa, (c) augmentation of holding capacity of loops and yard lines at Darsana, Benapole and Rohanpur stations, (d) construction of a rail link between Akhaura and Agartala, (e) gradual increase of the compatibility between rolling stocks of India and Bangladesh, (f) acquisition of flat wagons and covered wagons to handle the future transit/transshipment of traffic.

v. Considering limitations of Bangladesh roads, (2-lanes, built on lower design standards). Bangladesh inter-district road transporters should provide the logistic support to transfer goods/containers of Indian perishable and high-value commodities from one border station to the other border station across Bangladesh.

vi. Concerned governments should agree to (a) upgrade the access roads to all major land ports, to their national highway standards; (b) establish modern transshipment facilities at these land ports to facilitate simultaneous loading and unloading at several points, and (c) build warehouses for storage, as necessary.

vii. To make IWT more competitive, Bangladesh may agree to designate "Ashuganj" as the new transshipment port to allow transfer of goods/containers to Bangladesh inter-district multiaxle road transport vehicles for onward movement to the border point at Akhaura.

viii. To ensure safety and security, all concerned governments need to agree that goods and containers that will be transported across Bangladesh, shall have to go through scanning machine before loading and that these will move under bond with full insurance cover.

Vix. To facilitate faster clearance of goods/containers at the major land ports, all concerned governments require agreeing on the establishment of on-line customs IT connectivity.

\section{Conclusions}

The analysis presented in this paper clearly indicates that Bangladesh and its close neighbors, India, Nepal and Bhutan could gain considerably if regional connectivities are fully established by all modes, and transit/transshipment of goods/containers are allowed across Bangladesh. It would clearly be a win-win situation for all. 
Full exploitation of the opportunities of trading in transport services sub-regionally, will require considerable investment in order to expand capacity of the Bangladesh Transport System. But once the sub-regional transport connectivities are made operational, donor countries and agencies may come forward to assist. In the process, Bangladesh could initially earn annually around US\$500 million, with considerable multiplier effects in the economy. It is expected that this research will stimulate some useful ideas to the policy makers of the concerned countries and agencies involved in regional transport development. The research may also be useful to the professionals and researchers in regional transport development.

\section{References}

Dsa, G., 2001. “Trade between North Eastern Region and Bangladesh: Nature, Trends and Implications for Development Cooperation" paper presented in the seminar on India's Northeast and Bangladesh: Problems and Opportunities, in February 2001at Guwahati.

Rahmatullah, M., 2004. "Integrating Transport Systems of South Asia" in Sobhan, Rehamn (ed.) (2004) Promoting Cooperation in South Asia: An Agenda for $13^{\text {th }}$ SAARC Summit, Centre for Policy Dialogue and the University Press Ltd., Dhaka

RIS, 2004. "Transport Infrastructure and Linkages" in Future Direction of BIMSTEC: towards a By of Bengal Economic Community. New Delhi: RIS.

SASEC, 2005. "Sub-regionl Corridor Operational Efficiency Study- Draft Final Report" presented in the South Asia Sub-regional Economic Cooperation (SASEC) Third Working Group Meeting held in May 9-10, 2005, Bangkok, Thailand.

Sobhan, R., 2000. Rediscovering the Southern Silk Route: Integrating Asia's Transport Infrastructure, Dhaka Centre for Policy Dialogue and the University Press Ltd.

Subramanin, U., 2001. "Transport, Logistics, and trade Facilitation in the South Asia Sub-region" in Integration of Transport and trade Facilitation: Selected Regional Case Studies. Washington D.C.: The World Bank.

The Daily Star, 12 August, 1999.

The Daily Star, 24 August, 1999.

UN-ESCAP, 2002. "Expert Group Meeting on the Asian Highway Network", 8-10 May 2002, Bangkok.

Verghese, B. G., 1998. India's North East Resurgent: Ethnicity, Insurgency, Governance Developmen (,cited in Subramanin, 2001). New Delhi: Konark Publishers.

Zinn, W., 1999. "Mercosur: Preliminary assessment of the transportation infrastructure supporting supply chain efficiency", paper presented at the Regional Technical Workshop on Transport and Transit Facilitation jointly organized by the World Bank and UN ESCAP, 19-21 April, Bangkok, Thailand. 